\title{
The Serotonergic Projection from the Median Raphe Nucleus to the Ventral Hippocampus is Involved in the Retrieval of Fear Memory Through the Corticotropin-Releasing Factor
} Type 2 Receptor

\author{
Yu Ohmura' ${ }^{1,2}$, Takeshi Izumi', Taku Yamaguchi', Iku Tsutsui-Kimura', Takayuki Yoshida' \\ and Mitsuhiro Yoshioka*' \\ 'Department of Neuropharmacology, Hokkaido University Graduate School of Medicine, Sapporo, Japan; 'Department of Pharmacology, \\ University of Michigan, Ann Arbor, MI, USA
}

\begin{abstract}
Several different studies have separately established that serotonin, corticotropin-releasing factor (CRF) receptors, and the hippocampus are involved in fear memory retrieval. The main aim of this study is to connect these separate studies. To assess the levels of anxiety/fear, we used the contextual fear-conditioning test and the elevated plus maze test as memory-dependent and memory-independent tasks, respectively. We injected $C R F$ receptor antagonists or vehicle into the median raphe nucleus (MRN) 10 min before behavioral tests. As a result, $1000 \mathrm{ng}$ of astressin 2B ( $\mathrm{CRF}_{2}$ receptor antagonist), but not $250 \mathrm{ng}$ of antalarmin ( $\mathrm{CRF}$, receptor antagonist), significantly suppressed the expression rate of freezing behavior in the contextual fear-conditioning test. However, in the elevated plus maze test, there was no difference between astressin 2B-injected rats and saline-injected rats in the time spent in open arms. Neither the amount of exploratory behavior nor the moving distance in the EPM of astressin 2B-injected rats differed from that of vehicle-injected rats. Moreover, when we assessed the extracellular serotonin release in the ventral hippocampus in freely moving rats through in vivo microdialysis, it was shown that the blockade of the $\mathrm{CRF}_{2}$ receptor in the MRN suppressed serotonin release in the ventral hippocampus during fear memory retrieval. These results indicated that endogenous CRF and/or related ligands that were released in the MRN could activate the $\mathrm{CRF}_{2}$ receptor and stimulate serotonin release in the ventral hippocampus, thereby inducing fear memory retrieval. Neuropsychopharmacology (2010) 35, 127I-1278; doi:10.1038/npp.2009.229; published online 13 January 2010
\end{abstract}

Keywords: corticotropin-releasing hormone; hippocampus; fear; memory; 5-HT; median raphe nucleus

\section{INTRODUCTION}

The retrieval of contextual fear memory is an important factor in avoiding a previously encountered threat to life. However, patients with mental disorders, such as posttraumatic stress disorder and panic disorder, are often troubled by inappropriate retrieval of fear memory. Thus, the neural mechanism underlying fear memory retrieval should be elucidated to explore more efficient clinical treatments of these mental disorders.

Given that selective serotonin reuptake inhibitors are effective for the treatment of posttraumatic stress disorder (Zohar and Westenberg, 2000; Irons, 2005; Robert et al, 2006), serotonin is a strong candidate for involvement in the

*Correspondence: Professor M Yoshioka, Department of Neuropharmacology, Hokkaido University Graduate School of Medicine, NI5 W7, Kita-ku, Sapporo, Hokkaido, 060-8638, Japan, Tel: +8I II 706 5059, Fax: + 8 I I| 706 7872; E-mail: flute@med.hokudai.ac.jp Received 21 August 2009; revised 18 November 2009; accepted 19 November 2009 control of fear memory retrieval. In addition, it is well known that the hippocampus is a major brain region regulating contextual fear memory (Holt and Maren, 1999; Trivedi and Coover, 2004). However, to date there is only one study showing the relationship between serotonin release in the ventral hippocampus and fear memory retrieval (Wilkinson et al, 1996). Moreover, it remains unknown which brain regions and neurotransmitters modulate serotonin release in the hippocampus during the retrieval of fear memory.

In this study, we focused on the median raphe nucleus (MRN), which is one of the origins of serotonergic projections to the forebrain. Avanzi et al (1998) showed that the electrolytic lesion of the MRN remarkably reduced freezing behavior, which is a measure of fear memory retrieval. Moreover, the serotonergic neurons in the MRN project heavily to the hippocampus (Azmitia and Segal, 1978). Nevertheless, over the last 10 years, the involvement of the MRN in serotonin release in the hippocampus during the retrieval of fear memory and what modulates the 
activity of the MRN have remained to be elucidated, probably because of the difficulty of administering a microinjection into a deeply located and small nucleus such as the MRN. However, this does not mean that the MRN has a negligible role in fear memory retrieval.

One of the candidates for the endogenous modulator of MRN activity is the corticotropin-releasing factor (CRF), which is a 41 amino-acid neuropeptide (Vale et al, 1981). $\mathrm{CRF}_{1}$ and $\mathrm{CRF}_{2}$ receptors have thus far been identified in mammals (Hauger et al, 2003), and it has been shown that both $\mathrm{CRF}_{1}$ and $\mathrm{CRF}_{2}$ receptor mRNAs are expressed in the MRN (Bittencourt and Sawchenko, 2000). Moreover, several psychiatric disorders, such as major depression (Nemeroff et $a l, 1984$ ) and posttraumatic stress disorder (Baker et al, 1999), have been associated with increased concentrations of CRF in the cerebrospinal fluid (CSF).

Therefore, we examined the relationship between CRF receptors in the MRN and retrieval of fear memory by using CRF receptor antagonists. To assess the levels of anxiety/ fear, we used the contextual fear-conditioning test and the elevated plus maze test as memory-dependent and memoryindependent tasks, respectively. To discriminate the effects of CRF antagonists on the MRN from those on the dorsal raphe nucleus (DRN), which is another origin of serotonergic projections to the forebrain, we injected an effective antagonist into the DRN. Moreover, we examined the effects of an effective antagonist on extracellular serotonin release in the ventral hippocampus during fear memory retrieval by using in vivo microdialysis.

\section{MATERIALS AND METHODS}

\section{Animals}

The subjects were male adult Wistar rats (10-13 weeks old) supplied by Nippon SLC (Hamamatsu, Japan). They were housed in groups of two or three under an alternating lightdark cycle (light from 1900 to 0700 hours) at $\sim 21^{\circ} \mathrm{C}$. All testing was carried out in the dark period. The treatment of animals complied with the guidelines for the care and use of laboratory animals of the Animal Research Committee of the Hokkaido University Graduate School of Medicine.

\section{Drugs}

Antalarmin, a $\mathrm{CRF}_{1}$ receptor antagonist, was dissolved in a solution of $5 \%$ camphor, $5 \%$ ethanol, and $90 \%$ saline. Astressin (nonselective CRF receptor antagonist) and astressin $2 \mathrm{~B}\left(\mathrm{CRF}_{2}\right.$ receptor antagonist) were dissolved in saline containing $0.1 \%$ bovine serum albumin. All drugs were purchased from Sigma (St Louis, MO, USA). The doses of each antagonist were as follows: antalarmin, $250 \mathrm{ng}$; astressin, $250 \mathrm{ng}$; and astressin 2B, $1000 \mathrm{ng}$ in $0.5 \mu \mathrm{l}$ vehicle. These doses were determined on the basis of previous studies (Sajdyk and Gehlert, 2000; Henry et al, 2006; Lukkes et al, 2008).

\section{Surgical Procedure}

Rats were anesthetized with sodium pentobarbital $(50 \mathrm{mg} / \mathrm{kg}$, i.p.) and fixed in a stereotaxic frame (Narishige, Tokyo, Japan). A stainless-steel guide cannula (24 G, $13.5 \mathrm{~mm}$ long) was implanted $2 \mathrm{~mm}$ above the target sites at an angle of $22^{\circ}$. The stereotaxic coordinates for both the DRN and the MRN were as follows: $7.8 \mathrm{~mm}$ posterior to the bregma (both sites), 2.6 and $2.9 \mathrm{~mm}$ lateral to the midline, and 5.9 and $8.4 \mathrm{~mm}$ ventral to the dura, respectively (Paxinos and Watson, 2004). For microdialysis experiments (experiment 4), a guide cannula (AG-8, Eicom, Japan) was implanted into the ventral hippocampus: $5.3 \mathrm{~mm}$ posterior to the bregma, $5.0 \mathrm{~mm}$ lateral to the midline, and $4.2 \mathrm{~mm}$ ventral to the dura, in addition to the guide cannula for the intra-MRN injection. After surgery, rats were housed individually and allowed a 1-week recovery period before testing.

\section{Microinjection Procedure}

Ten minutes before the start of behavioral tests, the CRF antagonist or vehicle was injected into the MRN or DRN with a Hamilton microsyringe using a 30-G stainless-steel injector (15.5 mm long) attached to a polyethylene tube. The solution $(0.5 \mu \mathrm{l})$ was infused over a period of $1 \mathrm{~min}$ at constant flow by a microinjection pump (CMA100, Carnegie Medicine, Sweden), and the injector was left in place for $1 \mathrm{~min}$ after injection to allow diffusion.

\section{In Vivo Microdialysis}

A dialysis probe $(3 \mathrm{~mm}$ long and $0.22 \mathrm{~mm}$ in outer diameter; A-I-8-03, Eicom) was inserted through the guide cannula. The probe was perfused with artificial CSF $(2.7 \mathrm{mM} \mathrm{KCl}$, $140 \mathrm{mM} \mathrm{NaCl}, 1.2 \mathrm{mM} \mathrm{CaCl}, 1.0 \mathrm{mM} \mathrm{MgCl}_{2}, 0.3 \mathrm{mM}$ $\mathrm{NaH}_{2} \mathrm{PO}_{4}$, and $1.7 \mathrm{mM} \mathrm{Na} \mathrm{HPO}_{4}, \mathrm{pH} 7.2$ ) at a flow rate of $2 \mu \mathrm{l} / \mathrm{min}$. Rats were placed in plastic observational cages $\left(30 \times 30 \times 35 \mathrm{~cm}^{3}\right)$, and samples were collected every $10 \mathrm{~min}$. After the serotonin levels were stabilized, three baseline samples were collected. It took at least $3 \mathrm{~h}$ until the serotonin levels were stabilized. The average of these samples was used as baseline. Intra-MRN drug injections were then administered.

\section{Serotonin and Dopamine Analysis}

Serotonin and dopamine concentrations were measured in dialysates using HPLC (Eicompak PP-ODS $4.6 \mathrm{~mm}$ i.d. $\times 30 \mathrm{~mm}$, Eicom) with electrochemical detection (ECD300, Eicom), as described previously (Yoshioka et al, 1995; Matsumoto et al, 2005, 2008). The mobile phase, which consisted of $2.1 \mathrm{mM}$ sodium 1-decansulfonate, $0.1 \mathrm{mM}$ EDTA$2 \mathrm{Na} / 0.1 \mathrm{M}$ phosphate buffer ( $\mathrm{pH} 6.0$ ), and $1 \%(\mathrm{v} / \mathrm{v})$ methanol, was pumped at a rate of $1 \mathrm{ml} / \mathrm{min}$. Data are expressed as the percentage value of baseline, which was calculated as the average of three consecutive dialysates before drug injections. Areas under the curve (AUCs) values for the serotonin levels during the 20-40 min period were calculated.

\section{Contextual Fear-Conditioning Test}

Each rat was acclimated in a footshock box $(30.5 \times 24.1 \times$ $21.0 \mathrm{~cm}^{3}$, Med Associates) for $5 \mathrm{~min}$. This was followed by 10 2-s footshocks (shock intensity, $0.5 \mathrm{~mA}$ ) administered at 30-s intervals, except for the no-footshock controls, which did not receive footshocks. After the last footshock, rats were returned to their home cage. Twenty-four hours later, 
drug injections were administered. Ten minutes after the drug injections, each rat was returned to the footshock box without being shocked. Freezing behavior was defined as the lack of movement except for respiration, accompanied by an arched back and retraction of the ears (Fanselow, 1980), and used as a measure of fear memory retrieval. In the 15-min (experiments 1,2) or the 30-min testing period (experiment 4), the presence or absence of freezing was estimated by an automatic system (FreezeFrame, Actimetrics, USA) using a pixel difference method. The concordance between this automatic system and trained human observers is $>90 \%$. (Actimetrics). In experiment 4 , after the testing period, rats were returned to observational cages to continue microdialysis.

\section{Elevated Plus Maze Test}

The apparatus was made of wood and consisted of two open arms $\left(50 \times 10 \mathrm{~cm}^{2}\right)$ and two closed arms $\left(50 \times 10 \mathrm{~cm}^{2}\right)$ that extended from the central platform $\left(10 \times 10 \mathrm{~cm}^{2}\right)$. Closed arms were surrounded by $40 \mathrm{~cm}$-high sidewalls. The maze was elevated $50 \mathrm{~cm}$ above the floor, and the illumination of the room was set to 200 lux. Rats were placed on the central platform facing an open arm. The behavior of each rat was monitored by a CCD camera over a 5 -min testing period; the number of entries for each arm, the distance moved in the maze, and the time spent in each arm were recorded and automatically analyzed using a software package (LimeLight, Actimetrics). The total number of entries into the four arms and the distance moved in the maze were used as measures of locomotor activity. The time spent in and the number of entries into the open arms were used as measures of memory-independent fear because rats innately avoid open spaces (Treit et al, 1993). In this case, it is a little difficult to consider these parameters as an index of anxiety because rats clearly avoid a specific situation. Although it may be a controversial issue, we considered these parameters as measures of memory-independent fear in this study. The time spent in the open arms was quantified as a percentage of the total time spent in the four arms. The number of entries into the open arms was quantified as a percentage of the total number of entries into the four arms.

\section{Verification of Cannula and Dialysis Probe Placements}

After the completion of experiments, rats were killed under deep anesthesia (urethane, $2 \mathrm{~g} / \mathrm{kg}$, i.p.). The brain was rapidly removed and frozen in liquid nitrogen. Coronal sections (of $50-\mu \mathrm{m}$ thickness) were cut on a cryostat and thaw mounted onto slides. After drying, the sections were stained with toluidine blue, and cannula placements were verified under a microscope according to the atlas (Paxinos and Watson, 2004). Only data collected from rats with correct injection needle and probe placements were included in the final analysis (Figure 1).

Experiment 1: Effects of the Injection of CRF Receptor Antagonists into the MRN on Memory-Dependent Fear in the Contextual Fear-Conditioning Test

To examine whether endogenous CRF in the MRN is involved in the retrieval of fear memory and to determine
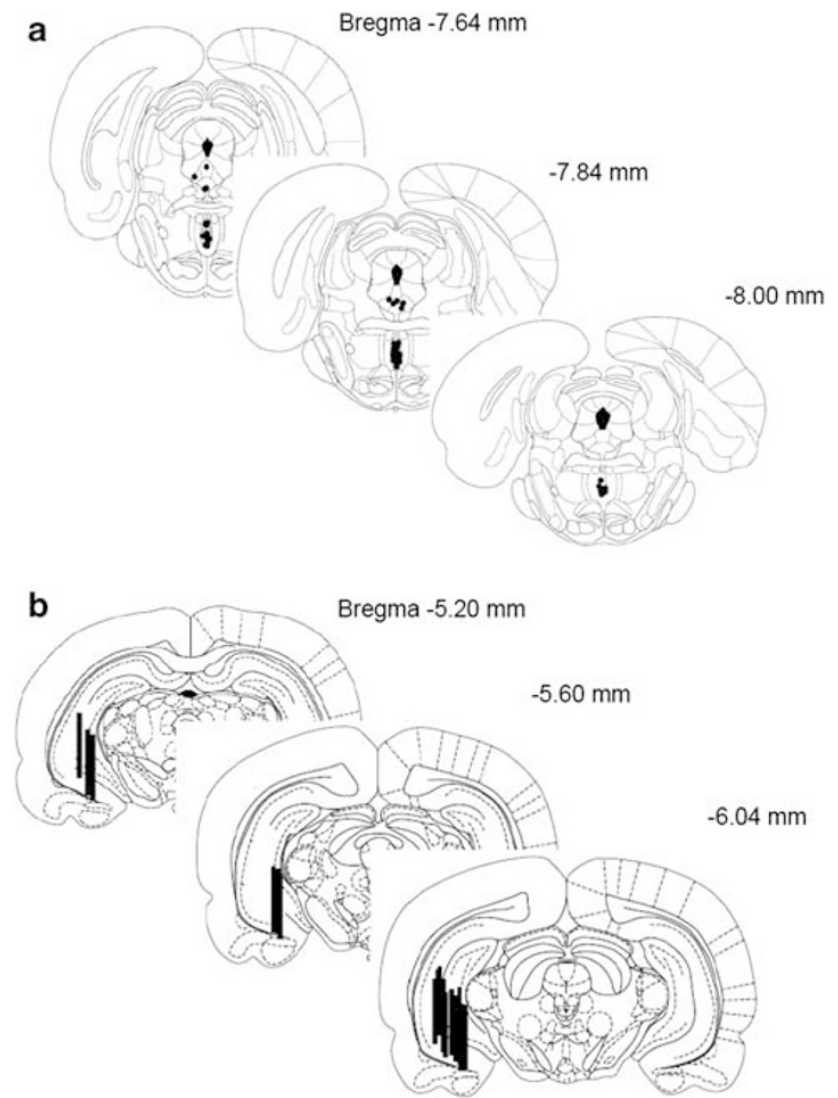

Figure I Cannula and probe placements. (a) Placements of the tip of the injectors in the DRN and MRN. (b) Placements of the microdialysis probe in the ventral hippocampus.

the subtype of CRF receptors in the MRN responsible for the effect of CRF on the retrieval of fear memory, we injected CRF receptor antagonists (antalarmin, $250 \mathrm{ng}$; astressin, $250 \mathrm{ng}$; and astressin $2 \mathrm{~B}, 1000 \mathrm{ng}$ ) or vehicle $(0.5 \mu \mathrm{l})$ into the MRN $10 \mathrm{~min}$ before the 15 -min contextual fear-conditioning test.

Experiment 2: Effects of the Injection of $\mathrm{CRF}_{2}$ Receptor Antagonist into the DRN on Memory-Dependent Fear in the Contextual Fear-Conditioning Test

To discriminate the effects of CRF antagonists on the MRN from those on the DRN, we injected an effective antagonist (astressin $2 \mathrm{~B}, 1000 \mathrm{ng})$ or vehicle $(0.5 \mu \mathrm{l})$ into the DRN 10 min before the 15 -min contextual fear-conditioning test.

Experiment 3: Effects of the Injection of $\mathrm{CRF}_{2}$ Receptor Antagonist into the MRN on Memory-Independent Fear in the Elevated Plus Maze Test

To discriminate fear memory retrieval (freezing behavior) from the increase in locomotor activity and memoryindependent fear responses, we further used the elevated plus maze test. We injected an effective antagonist (astressin 2B, $1000 \mathrm{ng}$ ) or vehicle $(0.5 \mu \mathrm{l})$ into the MRN $10 \mathrm{~min}$ before the 5 -min elevated plus maze test. 
Experiment 4: Effects of Intra-MRN Injection of $\mathrm{CRF}_{2}$ Receptor Antagonist on Extracellular Serotonin Release in the Ventral Hippocampus During Fear Memory Retrieval

To examine whether the $\mathrm{CRF}_{2}$ receptor modulates extracellular serotonin release in the hippocampus during the retrieval of fear memory, we used in vivo microdialysis in freely moving rats. We injected the $\mathrm{CRF}_{2}$ receptor antagonist (astressin $2 \mathrm{~B}, 1000 \mathrm{ng}$ ) or vehicle $(0.5 \mu \mathrm{l})$ into the MRN 10 min before the 30-min contextual fear-conditioning test. To discriminate the effects of fear memory retrieval on serotonin release from the effects of unconditioned stimuli, such as handling and exposure to the footshock box, on serotonin release, we further used no-footshock controls.

\section{Data Analysis}

In experiments 1-3, comparisons between groups were made by one-way analysis of variance (ANOVA). In experiment 4, two-way repeated ANOVA was also conducted to examine the time effects and the treatment effects on freezing behavior. For microdialysis data in experiment 4 , one-way ANOVA was used. Multiple comparisons with Bonferroni's correction were also conducted after each ANOVA. The $\alpha$-level was set at 0.05 for all comparisons. All statistical procedures were conducted using SPSS (version 15.0 J).

\section{RESULTS}

Experiment 1: Effects of the Injection of CRF Receptor Antagonists into the MRN on Memory-Dependent Fear in the Contextual Fear-Conditioning Test

The effect of antalarmin on freezing behavior was not significant (Figure 2a, also see Supplementary Figure S2), indicating that the $\mathrm{CRF}_{1}$ receptor in the MRN is not involved in the retrieval of fear memory. However, one-way ANOVA indicated a significant main effect of intra-MRN injections of CRF antagonists (astressin and astressin 2B) on freezing behavior $(\mathrm{F}(2,24)=14.81$, $P<0.01$, see Figure 2c). Moreover, post hoc comparisons showed that astressin and astressin $2 \mathrm{~B}$ significantly suppressed freezing behavior $(P<0.05$, see Figure $2 \mathrm{c})$, indicating that the $\mathrm{CRF}_{2}$ receptor in the MRN is involved in the retrieval of fear memory. Locations of cannula placements within the MRN are shown in Figure 1a. The typical injection site is shown in Supplementary Figure S1.

Experiment 2: Effects of the Injection of $\mathrm{CRF}_{2}$ Receptor Antagonist into the DRN on Memory-Dependent Fear in the Contextual Fear-Conditioning Test

The effect of intra-DRN injection of astressin 2B (1000 ng) on freezing behavior was not significant (Figure 2b), indicating that the effects of intra-MRN injection of astressin $2 \mathrm{~B}$ described above were not due to the leakage of astressin 2B to the DRN. Locations of cannula placements within the DRN are shown in Figure 1a.
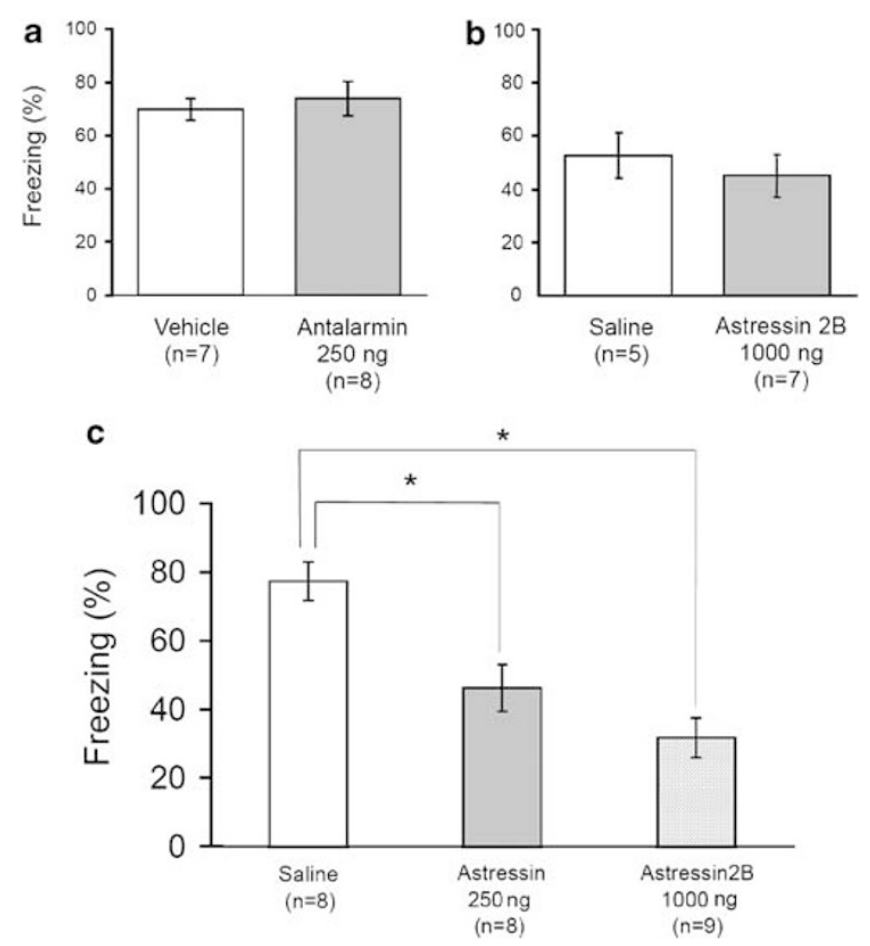

Figure 2 Effect of intra-MRN or DRN injection of CRF antagonists on freezing behavior in contextual fear-conditioning test. Ten minutes before the start of behavioral tests, CRF antagonists or vehicles were injected. Bars represent mean freezing rate and lines represent SEM. (a) Effect of intraMRN injection of antalarmin on freezing behavior. (b) Effect of intra-DRN injection of astressin 2B on freezing behavior. (c) Effects of intra-MRN injection of astressin and astressin $2 \mathrm{~B}$ on freezing behavior. $* P<0.05$.

Experiment 3: Effects of the Injection of $\mathrm{CRF}_{2}$ Receptor Antagonist into the MRN on Memory-Independent Fear in the Elevated Plus Maze Test

In this study, none of the parameters in the elevated plus maze test (such as time spent in the open arms, number of entries into the open arms, total number of entries into the four arms, and distance moved in the maze) were significantly affected by intra-MRN injection of astressin 2B (Table 1). The dose of astressin 2B (1000 ng) that had affected freezing behavior did not alter memory-independent fear expression or locomotor activity.

Experiment 4: Effects of Intra-MRN Injection of $\mathrm{CRF}_{2}$ Receptor Antagonist on Extracellular Serotonin Release in the Ventral Hippocampus During Fear Memory

\section{Retrieval}

One-way ANOVA indicated a significant main effect of treatment conditions on extracellular serotonin release in the ventral hippocampus $(F(2,15)=22.52, P<0.001$, see Figure 3). Post hoc comparisons showed that AUCs during re-exposure to the footshock box in the saline-treated footshock group was significantly higher than that of the saline-treated no-footshock controls $(P<0.05$, see Figure 3$)$, consistent with a previous study (Wilkinson et al, 1996). Moreover, the increase in serotonin release was significantly attenuated by the intra-MRN injection of astressin 2B $(P<0.05$, see Figure 3$)$. Locations of probe placements within the ventral hippocampus are shown in Figure $1 \mathrm{~b}$. 
Table I Memory-Independent Fear Expression and Locomotor Activity in the Elevated Plus Maze Test

\begin{tabular}{lll}
\hline & \multicolumn{2}{c}{ Treatment } \\
\cline { 2 - 3 } & Saline $(\mathbf{n}=\mathbf{7})$ & $\begin{array}{c}\text { Astressin 2B } \\
(\mathbf{n}=\mathbf{7})\end{array}$ \\
\hline Time spent in the open arms (\%) & $35.66 \pm 9.04$ & $21.42 \pm 6.20$ \\
Entries into the open arms (\%) & $44.24 \pm 7.89$ & $38.98 \pm 7.45$ \\
Total number of entries into the & $14.43 \pm 2.82$ & $17.29 \pm 1.67$ \\
four arms & & \\
Moving distance on the maze $(\mathrm{cm})$ & $1107.63 \pm 107.56$ & $1056.57 \pm 130.58$ \\
\hline
\end{tabular}

The mean \pm SEM for each parameter is given. The dose of astressin $2 B$ is $1000 \mathrm{ng}$.
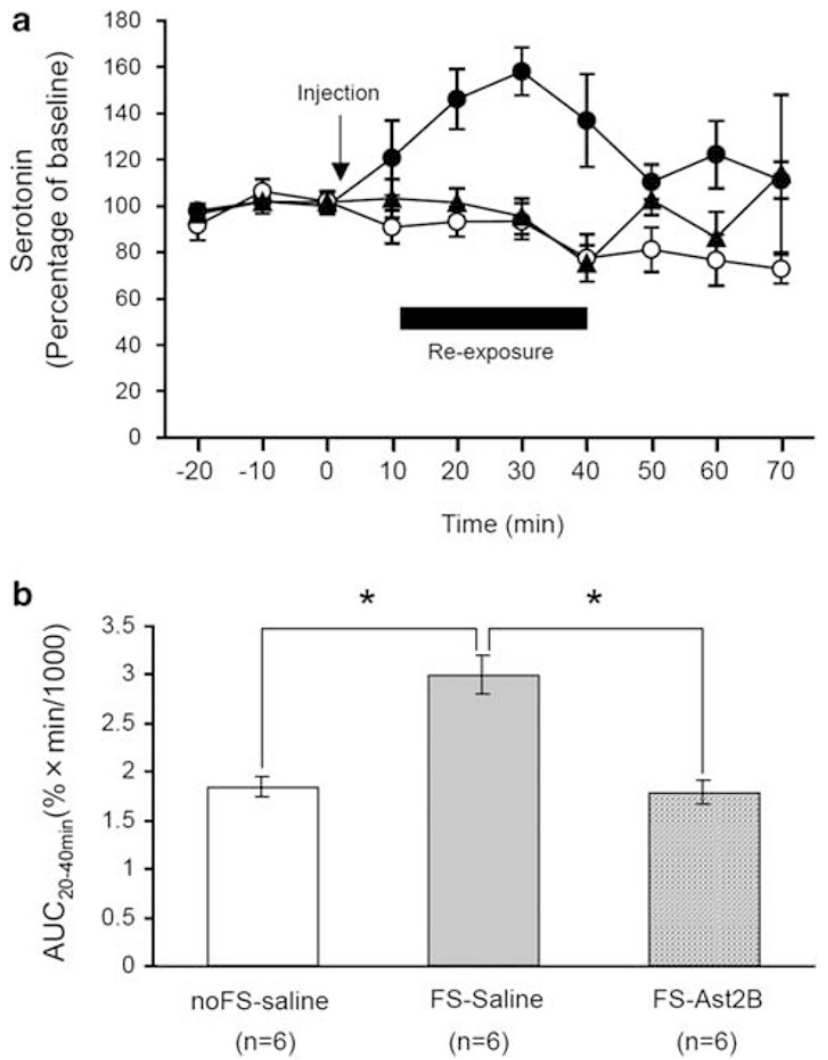

Figure 3 Effects of intra-MRN injection of astressin 2B on extracellular serotonin release in the ventral hippocampus. (a) The time course of extracellular serotonin level changes. Filled circles $(n=6)$ represent rats that had received footshock $24 \mathrm{~h}$ before re-exposure and received an injection of saline on the testing day (FS-saline). Open circles $(n=6)$ represent rats that had received footshock and received an injection of astressin 2B (FS-Ast2B). Filled triangles $(n=6)$ represent rats that had been placed in the footshock box without footshock and received an injection of saline (no-FS-saline). Slightly high serotonin levels and extremely large SEM in the no-FS-saline group during the 70-min period are due to only one rat that showed extremely high serotonin level in the 70-min period. We did not exclude this rat from data because it did not show any abnormal behavior and the serotonin levels in this rat returned to normal levels only $20 \mathrm{~min}$ after this time period (we continued to collect samples only in this rat). (b) The area under the curve (AUC) of extracellular serotonin levels during re-exposure to footshock box. Data are given as mean AUC \pm SEM $* P<0.05$.

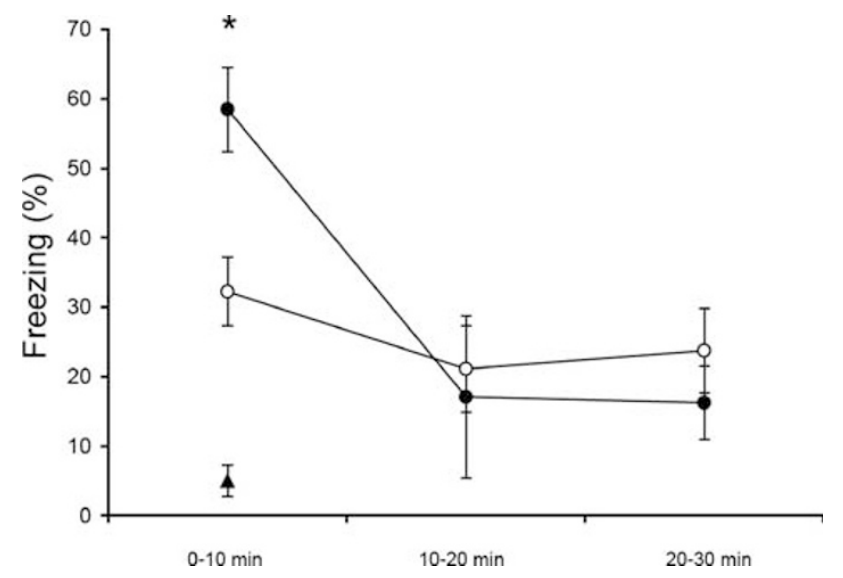

Figure 4 Effects of intra-MRN injection of astressin 2B on freezing behavior in contextual fear-conditioning test with microdialysis. Filled circles $(n=6)$ represent rats that had received footshock $24 \mathrm{~h}$ before re-exposure and received an injection of saline on the testing day. Open circles $(n=6)$ represent rats that had received footshock and received an injection of astressin 2B. Filled triangles $(n=6)$ represent rats that had been placed in the footshock box without footshock and received an injection of saline. We excluded the data on no-footshock controls in the statistical analysis because no-footshock controls rarely moved in the 10-30 min phase, and the automatic system could not discriminate between freezing and unmoving. Data are given as mean \pm SEM $* P<0.05$.

Experiment 4: Effects of the Injection of $\mathrm{CRF}_{2}$ Receptor Antagonist into the MRN on Memory-Dependent Fear in the Contextual Fear-Conditioning Test With Microdialysis

Two-way ANOVA showed a significant time effect $(F(2,20)$ $=16.59, P<0.001$, see Figure 4$)$ and a significant timeconditions interaction $(\mathrm{F}(2,20)=6.44, P<0.01$, see Figure 4$)$ on freezing behavior, although a significant main effect of conditions was not observed. Post hoc comparisons showed that intra-MRN injections of astressin 2B suppressed freezing behavior only in the $0-10 \mathrm{~min}$ phase $(P<0.05$, see Figure 4).

\section{DISCUSSION}

In this study, intra-MRN injections of astressin $2 \mathrm{~B}\left(\mathrm{CRF}_{2}\right.$ receptor antagonist) and astressin (nonselective CRF receptor antagonist) significantly suppressed memorydependent fear expression in the contextual fear-conditioning test, whereas neither intra-DRN injection of astressin $2 \mathrm{~B}$ nor intra-MRN injection of antalarmin $\left(\mathrm{CRF}_{1}\right.$ receptor antagonist) had any effect. Although it seems that intraDRN injection itself affected freezing behavior (Figure 2), it was likely due to damaging the ventral periaqueductal gray (De Oca et al, 1998; Vianna et al, 2001). Furthermore, intraMRN injection of astressin 2B did not affect memoryindependent fear expression or locomotor activity in the elevated plus maze test. Ohmura et al (2008) showed that intra-MRN injection of CRF did not affect memoryindependent fear expression or locomotor activity in the elevated plus maze test. Andrade and Graeff (2001) showed that serotonergic lesion of the MRN did not affect memoryindependent fear expression in the elevated plus maze test, and Andrade et al (2004) showed that serotonergic lesion of 
the MRN affected conditioned fear, but not unconditioned fear, in the T-maze test. These findings are consistent with those of previous studies. The results indicate that endogenous CRF could facilitate the retrieval of fear memory through the activation of the $\mathrm{CRF}_{2}$ receptor. This is the first study to indicate the involvement of endogenous CRF within the MRN in fear memory retrieval and to identify the subtype of CRF receptors in the MRN responsible for fear memory retrieval.

We also showed that serotonin release in the ventral hippocampus during the retrieval of fear memory increased, consistent with one previous study (Wilkinson et al, 1996). Moreover, we found that the increase in serotonin release in the ventral hippocampus was significantly attenuated by intra-MRN injection of astressin 2B. Given that several previous studies have shown that the ventral hippocampus is involved in fear memory retrieval (Trivedi and Coover, 2004; Hobin et al, 2006; Burman et al, 2006), these results indicate that endogenous CRF release could activate the $\mathrm{CRF}_{2}$ receptor in the MRN and stimulate serotonin release in the ventral hippocampus, and thereby induce fear memory retrieval. This is the first study to indicate that the serotonergic projection from the MRN to the ventral hippocampus is involved in the retrieval of fear memory through the $\mathrm{CRF}_{2}$ receptor in the MRN.

Supplementary data also support our findings. A higher dose of antalarmin did not show clear effects on fear memory retrieval (Supplementary Figure S2). When we analyzed data from animals that had cannula placements outside the MRN, there were no clear effects of astressin $2 \mathrm{~B}$ on freezing behavior (Supplementary Figure S3). Dopamine release in the ventral hippocampus was not altered by exposure to the footshock box or intra-MRN injection of astressin 2B (Supplementary Figure S4). Although dopamine receptors in the ventral hippocampus are involved in working memory and complex learning (Wilkerson and Levin, 1999; Umegaki et al, 2001), they may not be involved in fear memory retrieval. Moreover, preliminary data showed that the serotonin release in the dorsal hippocampus was not altered by exposure to footshock box (Supplementary Figure S5), although serotonin release in the dorsal hippocampus would be involved in stress responses other than fear memory retrieval (Matsuo et al, 1996; Muchimapura et al, 2002). These data also support our conclusion that the serotonergic projection from the MRN to the ventral hippocampus is selectively involved in the retrieval of fear memory through the $\mathrm{CRF}_{2}$ receptor in the MRN.

Although promising, there are at least six unresolved issues in this study. First, it is possible that endogenous CRF-related peptides such as urocortin, but not CRF itself, in the MRN (Bittencourt et al, 1999) may induce fear memory retrieval through the activation of the $\mathrm{CRF}_{2}$ receptor. It is necessary to assess the extracellular levels of CRF and/or urocortin in the MRN during fear memory retrieval to decipher this interesting question in future studies. Little is known about the role of urocortin in fear memory at this time (Pan and Kastin, 2008).

Second, we cannot completely exclude the possibility that CRF and/or related peptides in the MRN affect memoryindependent fear expression because the controllability of stress differs between the elevated plus maze test and the contextual fear-conditioning test. The effect of CRF and/or related peptides in the MRN should be examined in different types of tests in future studies. However, it should be noted that Andrade et al (2004) showed that serotonergic lesion of the MRN affected conditioned fear, but not unconditioned fear, in another type of test.

Third, it should also be noted that some studies have raised a question about the role of the MRN in fear memory retrieval because the microinjection of a serotonergic $5-\mathrm{HT}_{1 \mathrm{~A}}$ agonist into the MRN did not affect contextual fear-potentiated startle, whereas it decreased freezing in the contextual fear-conditioning test (Borelli et al, 2005; Almada et al, 2009). Several other types of tests should be conducted in future studies to settle this issue.

Fourth, we cannot completely deny the possibility that the $\mathrm{CRF}_{2}$ receptor in the DRN and in the MRN is also involved in fear memory retrieval because previous studies have shown that the $\mathrm{CRF}_{2}$ receptor in the DRN is involved in fear conditioning. However, these studies focused on conditioning and not memory retrieval (drug injections were administered before fear conditioning; Hammack et al, 2002, 2003). Although our results showed that intra-DRN injection of astressin $2 \mathrm{~B}$ had no effects on fear memory retrieval (Figure $2 \mathrm{~b}$ ), they do not completely rule out the possibility that the $\mathrm{CRF}_{2}$ receptor in the DRN is involved in fear memory retrieval because it was shown that the effects of intra-DRN injection of CRF are subregion dependent (Hammack et al, 2002), and we did not intend to examine subregion-specific effects. We used a larger volume $(0.5 \mu \mathrm{l})$ for drug injections, whereas Hammack et al (2002) used a smaller volume $(0.25 \mu \mathrm{l})$ to elucidate the site specificity. However, it is reasonable because our aim was to examine whether the effects of intra-MRN injection of astressin $2 B$ in this study were due to the leakage of astressin $2 \mathrm{~B}$ to the DRN. It is also possible that the MRN is involved in the retrieval of fear memory, whereas the DRN is involved in the acquisition of fear memory.

Fifth, our results did not directly prove the causal relationship between serotonin release in the ventral hippocampus and fear memory retrieval, although we showed the association between them. However, the significant increase in serotonin release started soon after re-exposure to the footshock box (Figure 3a). Given that the concentration of serotonin assessed by microdialysis and HPLC reflects the serotonin release of several minutes before, it is likely that the increase in serotonin release preceded the retrieval of fear memory. Moreover, serotonin levels in the ventral hippocampus were still elevated in rats that had received footshock $24 \mathrm{~h}$ before re-exposure and received an injection of saline on the testing day (FS-saline group) even after animals started to stop freezing (Figures 3 and 4). We speculated that rats still retrieved fear memory during the $10-30 \mathrm{~min}$ phase. The reasons are twofold. First, the concentration of extracellular serotonin was decreased immediately after removing rats from the footshock box, which is a contextual stimulus (Figure 3). Second, rats in the FS-saline group alternated between freezing and exploratory behavior. Exploratory behavior during the $10-30 \mathrm{~min}$ phase is probably coping behavior to the dangerous situation because no-footshock controls were in a resting posture and did not move the during 10-30 min phase (data not shown). Further studies using serotonin receptor antagonists will be required to determine the causal relationship. 
Finally, it should also be noted that intra-MRN injection of astressin 2B did not completely suppress freezing behavior (Figures 2 and 4), whereas it almost completely suppressed serotonin release in the ventral hippocampus (Figure 3). This indicates that there are also other systems regulating the retrieval of fear memory. For example, many previous studies suggest that the amygdala is also involved in fear memory retrieval (for a review, see LeDoux, 2000).

In conclusion, this study suggests that the release of endogenous CRF and/or related ligands could activate the $\mathrm{CRF}_{2}$ receptor in the MRN and stimulate serotonin release in the ventral hippocampus, thereby inducing fear memory retrieval. Although several different studies have separately established that serotonin, CRF receptors, and the hippocampus are involved in fear memory retrieval, these distinct lines of study have not been linked to each other. We found that the MRN could be the key connecting these separate studies. The $\mathrm{CRF}_{2}$ receptor in the MRN could have a pivotal role in fear memory retrieval and could be a target of drug development for the treatment of mental disorders involving fear memory, such as posttraumatic stress disorder.

\section{ACKNOWLEDGEMENTS}

This study was supported by a Grant-in-Aid for Scientific Research from the Ministry of Education, Culture, Sports, Science and Technology, Japan (20390309).

\section{DISCLOSURE}

The authors declare no conflict of interest.

\section{REFERENCES}

Almada RC, Borelli KG, Albrechet-Souza L, Brandão ML (2009). Serotonergic mechanisms of the median raphe nucleus-dorsal hippocampus in conditioned fear: output circuit involves the prefrontal cortex and amygdala. Behav Brain Res 203: 279-287.

Andrade TG, Graeff FG (2001). Effect of electrolytic and neurotoxic lesions of the median raphe nucleus on anxiety and stress. Pharmacol Biochem Behav 70: 1-14.

Andrade TG, Macedo CE, Zangrossi Jr H, Graeff FG (2004). Anxiolytic-like effects of median raphe nucleus lesion in the elevated T-maze. Behav Brain Res 153: 55-60.

Avanzi V, Castilho VM, de Andrade TGCS, Brandao ML (1998). Regulation of contextual conditioning by the median raphe nucleus. Brain Res 790: 178-184.

Azmitia EC, Segal M (1978). An autoradiographic analysis of the differential ascending projections of the dorsal and median raphe nuclei in the rat. J Comp Neurol 179: 641-667.

Baker DG, West SA, Nicholson WE, Ekhator NN, Kasckow JW, Hill KK et al. (1999). Serial CSF corticotropin-releasing hormone levels and adrenocortical activity in combat veterans with posttraumatic stress disorder. Am J Psychiatry 156: 585-588.

Bittencourt JC, Vaughan J, Arias C, Rissman RA, Vale WW, Sawchenko PE (1999). Urocortin expression in rat brain: evidence against a pervasive relationship of urocortin-containing projections with targets bearing type 2 CRF receptors. J Comp Neurol 415: 285-312.

Bittencourt JC, Sawchenko PE (2000). Do centrally administered neuropeptides access cognate receptors? An analysis in the central corticotropin-releasing factor system. J Neurosci 20: $1142-1156$.
Borelli KG, Gárgaro AC, dos Santos JM, Brandão ML (2005). Effects of inactivation of serotonergic neurons of the median raphe nucleus on learning and performance of contextual fear conditioning. Neurosci Lett 387: 105-110.

Burman MA, Starr MJ, Gewirtz JC (2006). Dissociable effects of hippocampus lesions on expression of fear and trace fear conditioning memories in rats. Hippocampus 16: 103-113.

De Oca BM, DeCola JP, Maren S, Fanselow MS (1998). Distinct regions of the periaqueductal gray are involved in the acquisition and expression of defensive responses. $J$ Neurosci 18: 3426-3432.

Fanselow MS (1980). Conditioned and unconditional components of post-shock freezing. Pavlov J Biol Sci 15: 177-182.

Hammack SE, Richey KJ, Schmid MJ, LoPresti ML, Watkins LR, Maier SF (2002). The role of corticotropin-releasing hormone in the dorsal raphe nucleus in mediating the behavioral consequences of uncontrollable stress. $J$ Neurosci 22: 1020-1026.

Hammack SE, Schmid MJ, LoPresti ML, Der-Avakian A, Pellymounter MA, Foster AC et al. (2003). Corticotropin releasing hormone type 2 receptors in the dorsal raphe nucleus mediate the behavioral consequences of uncontrollable stress. J Neurosci 23: 1019-1025.

Hauger RL, Grigoriadis DE, Dallman MF, Plotsky PM, Vale WW, Dautzenberg FM (2003). International union of pharmacology. XXXVI. Current status of the nomenclature for receptors for corticotropin-releasing factor and their ligands. Pharmacol Rev 55: 21-26.

Henry B, Vale W, Markou A (2006). The effect of lateral septum corticotropin-releasing factor receptor 2 activation on anxiety is modulated by stress. J Neurosci 26: 9142-9152.

Hobin JA, Ji J, Maren S (2006). Ventral hippocampal muscimol disrupts context-specific fear memory retrieval after extinction in rats. Hippocampus 16: 174-182.

Holt W, Maren S (1999). Muscimol inactivation of the dorsal hippocampus impairs contextual retrieval of fear memory. J Neurosci 19: 9054-9062.

Irons J (2005). Fluvoxamine in the treatment of anxiety disorders. Neuropsychiatr Dis Treat 1: 289-299.

LeDoux JE (2000). Emotion circuits in the brain. Annu Rev Neurosci 23: 155-184.

Lukkes JL, Forster GL, Renner KJ, Summers CH (2008). Corticotropin-releasing factor 1 and 2 receptors in the dorsal raphe differentially affect serotonin release in the nucleus accumbens. Eur J Pharmacol 578: 185-193.

Matsumoto M, Togashi H, Kaku A, Kanno M, Tahara K, Yoshioka M (2005). Cortical GABAergic regulation of dopaminergic responses to psychological stress in the rat dorsolateral striatum. Synapse 56: 117-121.

Matsumoto M, Shikanai H, Togashi H, Izumi T, Kitta T, Hirata R et al. (2008). Characterization of clozapine-induced changes in synaptic plasticity in the hippocampal-mPFC pathway of anesthetized rats. Brain Res 1195: 50-55.

Matsuo M, Kataoka Y, Mataki S, Kato Y, Oi K (1996). Conflict situation increases serotonin release in rat dorsal hippocampus: in vivo study with microdialysis and Vogel test. Neurosci Lett 215: $197-200$.

Muchimapura S, Fulford AJ, Mason R, Marsden CA (2002). Isolation rearing in the rat disrupts the hippocampal response to stress. Neuroscience 112: 697-705.

Nemeroff CB, Widerlöv E, Bissette G, Walléus H, Karlsson I, Eklund $\mathrm{K}$ et al. (1984). Elevated concentrations of CSF corticotropin-releasing factor-like immunoreactivity in depressed patients. Science 226: 1342-1344.

Ohmura Y, Yamaguchi T, Izumi T, Matsumoto M, Yoshioka M (2008). Corticotropin releasing factor in the median raphe nucleus is involved in the retrieval of fear memory in rats. Eur J Pharmacol 584: 357-360. 
Pan W, Kastin AJ (2008). Urocortin and the brain. Prog Neurobiol 84: $148-156$.

Paxinos G, Watson C (2004). The Rat Brain in Stereotaxic Coordinates 5th edn Academic Press: San Diego.

Robert S, Hamner MB, Ulmer HG, Lorberbaum JP, Durkalski VL (2006). Open-label trial of escitalopram in the treatment of posttraumatic stress disorder. J Clin Psychiatry 67: 1522-1526.

Sajdyk TJ, Gehlert DR (2000). Astressin, a corticotropin releasing factor antagonist, reverses the anxiogenic effects of urocortin when administered into the basolateral amygdala. Brain Res 877: 226-234.

Treit D, Menard J, Royan C (1993). Anxiogenic stimuli in the elevated plus-maze. Pharmacol Biochem Behav 44: 463-469.

Trivedi MA, Coover GD (2004). Lesions of the ventral hippocampus, but not the dorsal hippocampus, impair conditioned fear expression and inhibitory avoidance on the elevated T-maze. Neurobiol Learn Mem 81: 172-184.

Umegaki H, Munoz J, Meyer RC, Spangler EL, Yoshimura J, Ikari H et al. (2001). Involvement of dopamine $\mathrm{D}(2)$ receptors in complex maze learning and acetylcholine release in ventral hippocampus of rats. Neuroscience 103: 27-33.
Vale W, Spiess J, Rivier C, Rivier J (1981). Characterization of a 41residue ovine hypothalamic peptide that stimulates secretion of corticotropin and beta-endorphin. Science 213: 1394-1397.

Vianna DM, Graeff FG, Landeira-Fernandez J, Brandão ML (2001). Lesion of the ventral periaqueductal gray reduces conditioned fear but does not change freezing induced by stimulation of the dorsal periaqueductal gray. Learn Mem 8: 164-169.

Wilkerson A, Levin ED (1999). Ventral hippocampal dopamine D1 and D2 systems and spatial working memory in rats. Neuroscience 89: 743-749.

Wilkinson LS, Humby T, Killcross S, Robbins TW, Everitt BJ (1996). Dissociations in hippocampal 5-hydroxytryptamine release in the rat following Pavlovian aversive conditioning to discrete and contextual stimuli. Eur J Neurosci 8: 1479-1487.

Yoshioka M, Matsumoto M, Togashi H, Saito H (1995). Effects of conditioned fear stress on 5-HT release in the rat prefrontal cortex. Pharmacol Biochem Behav 51: 515-519.

Zohar J, Westenberg HG (2000). Anxiety disorders: a review of tricyclic antidepressants and selective serotonin reuptake inhibitors. Acta Psychiatr Scand 403: 39-49.

Supplementary Information accompanies the paper on the Neuropsychopharmacology website (http://www.nature.com/npp) 